\title{
High-Frequency Oscillatory Ventilation Use and Severe Pediatric ARDS in the Pediatric Hematopoietic Cell Transplant Recipient
}

\author{
Courtney M Rowan MD, Ashley Loomis MD, Jennifer McArthur DO, Lincoln S Smith MD, \\ Shira J Gertz MD, Julie C Fitzgerald MD PhD, Mara E Nitu MD, Elizabeth AS Moser MSc, \\ Deyin D Hsing MD, Christine N Duncan MD, Kris M Mahadeo MD MPH, Jerelyn Moffet NP, \\ Mark W Hall MD, Emily L Pinos CRNP MSN, Robert F Tamburro MD, Ira M Cheifetz MD; and \\ the Investigators of the Pediatric Acute Lung Injury and Sepsis Network
}

\begin{abstract}
INTRODUCTION: The effectiveness of high-frequency oscillatory ventilation (HFOV) in the pediatric hematopoietic cell transplant patient has not been established. We sought to identify current practice patterns of $\mathrm{HFOV}$, investigate parameters during HFOV and their association with mortality, and compare the use of HFOV to conventional mechanical ventilation in severe pediatric ARDS. METHODS: This is a retrospective analysis of a multi-center database of pediatric and young adult allogeneic hematopoietic cell transplant subjects requiring invasive mechanical ventilation for critical illness from 2009 through 2014. Twelve United States pediatric centers contributed data. Continuous variables were compared using a Wilcoxon rank-sum test or a KruskalWallis analysis. For categorical variables, univariate analysis with logistic regression was performed. RESULTS: The database contains 222 patients, of which 85 subjects were managed with HFOV. Of this HFOV cohort, the overall pediatric ICU survival was $23.5 \%(n=20)$. HFOV survivors were transitioned to HFOV at a lower oxygenation index than nonsurvivors (25.6, interquartile range 21.1-36.8, vs 37.2, interquartile range 26.5-52.2, $P=.046)$. Survivors were transitioned to HFOV earlier in the course of mechanical ventilation, (day 0 vs day $2, P=.002$ ). No subject survived who was transitioned to HFOV after 1 week of invasive mechanical ventilation. We compared subjects with severe pediatric ARDS treated only with conventional mechanical ventilation versus early HFOV (within $2 \mathrm{~d}$ of invasive mechanical ventilation) versus late HFOV. There was a trend toward difference in survival (conventional mechanical ventilation $24 \%$, early HFOV $30 \%$, and late HFOV 9\%, $P=.08)$. CONCLUSIONS: In this large database of pediatric allogeneic hematopoietic cell transplant subjects who had acute respiratory failure requiring invasive mechanical ventilation for critical illness with severe pediatric ARDS, early use of HFOV was associated with improved survival compared to late implementation of HFOV, and the subjects had outcomes similar to those treated only with conventional mechanical ventilation. Key words: hematopoietic stem cell transplantation; critical care; respiratory insufficiency; artificial respiration; high frequency ventilation; mortality; respiratory distress syndrome; adult. [Respir Care 2018;63(4):404-411. (C) 2018 Daedalus Enterprises]
\end{abstract}

Introduction

The pediatric allogeneic hematopoetic cell transplant patient admitted to the pediatric ICU has a high mortality risk. While outcomes for these patients have improved, ${ }^{1}$ respiratory failure and mechanical ventilation continue to be associated with high mortality. ${ }^{2-5}$ These patients are at high risk of severe pulmonary complications when re- spiratory failure develops. ${ }^{6-8}$ Immunodeficiency is a risk factor for the development of pediatric ARDS and related mortality. The vast majority of pediatric hematopoietic cell transplant patients intubated for respiratory failure develop pediatric ARDS within the first week of ventilation. ${ }^{9}$

High-frequency oscillatory ventilation (HFOV) is a common rescue modality utilized in pediatric ARDS. Data 
supporting its use in pediatric ARDS demonstrate an improvement in oxygenation. ${ }^{10-14}$ However, emerging data question the effect of HFOV on meaningful outcomes. Some studies have suggested that HFOV use may be associated with a higher mortality and a longer duration of ventilation even when severity of illness markers are incorporated into the analyses. ${ }^{15,16}$ In the adult population, HFOV use has been found to not improve survival. One trial was stopped early due to a higher mortality rate, increased sedation and neuromuscular blockade, and more vasoactive agents in the HFOV group. In pediatrics, unfortunately, the available data do not allow for an evidence-based application of HFOV in the management of pediatric ARDS. Furthermore, the effectiveness of HFOV in unique and highly vulnerable populations, such as pediatric hematopoietic cell transplant patients, has not been established.

We sought to establish current practice patterns of HFOV in the pediatric allogeneic hematopoietic cell transplant patient, investigate parameters during HFOV and their association with mortality, and compare HFOV use to conventional mechanical ventilation in patients with severe pediatric ARDS.

\section{Methods}

This is a secondary analysis of a retrospective multicenter database. Twelve centers contributed up to 25 of their most recent, consecutive, pediatric allogeneic hematopoietic cell transplant patients who had acute respiratory failure requiring invasive mechanical ventilation. All indications for allogeneic hematopoietic cell transplant were included. Subjects were included if they were between the ages of 1 month and $21 \mathrm{y}$. Autologous transplant patients were excluded. Patients who were admitted prior to Jan-

Drs Rowan and Nitu are affiliated with the Department of Pediatrics, Division of Critical Care, Riley Hospital for Children, Indiana University School of Medicine, Indianapolis, IN. Dr Loomis is affiliated with the Department of Pediatrics, Division of Critical Care, University of Minnesota Masonic Children's Hospital, University of Minnesota, Minneapolis, MN. Dr McArthur is affiliated with the Department of Pediatrics, Division of Critical Care, St. Jude's Children's Research Hospital, Memphis, TN. Dr Smith is affiliated with the Department of Pediatrics, Division of Pediatric Critical Care Medicine, Seattle Children's Hospital, University of Washington, Seattle, WA. Dr Gertz is affiliated with the Department of Pediatrics, Division of Critical Care, St. Barnabas Medical Center, Livingston, NJ. Dr Fitzgerald is affiliated with the Department of Anesthesiology and Critical Care, Division of Critical Care, Children's Hospital of Philadelphia, University of Pennsylvania Perelman School of Medicine, Philadelphia, PA. Ms Moser is affiliated with the Department of Biostatistics, Indiana University, Indianapolis, IN. Dr Hsing is affiliated with the Department of Pediatrics, Division of Critical Care, Weil Cornell Medical College, New York Presbyterian Hospital, New York, NY. Dr Duncan is affiliated with the Department of Pediatrics, Division of Oncology, Dana-Farber Cancer Institute Harvard University, Boston,

\section{QUICK LOOK}

\section{Current knowledge}

Although high-frequency oscillatory ventilation (HFOV) is commonly used in pediatric ARDS, the effectiveness of this modality remains unclear. Many studies suggest an improvement in oxygenation, yet other studies suggest its use may be associated with higher mortality and longer duration of ventilation. The currently available data do not allow for an evidence-based application of HFOV. Furthermore, the application of HFOV in the pediatric hematopoietic cell transplant patient has not been established.

\section{What this paper contributes to our knowledge}

In pediatric and young adults after hematopoietic cell transplant with severe pediatric ARDS, those who survived had continued improvement in oxygenation throughout an HFOV course. Also, earlier use of HFOV was associated with improved survival compared to those who were transitioned later in the course of mechanical ventilation. Late transition to HFOV, especially after $7 \mathrm{~d}$ of mechanical ventilation, should be done with caution.

uary 1, 2009, were also excluded from the study to ensure the data would be as relevant to current practice as possible. Institutional review board approval was obtained at each individual center prior to the start of data collection.

\footnotetext{
MA. Dr Mahadeo is affiliated with the Department of Pediatrics, Division of Oncology, Children's Hospital at Montefiore, Albert Einstein College of Medicine, Bronx, NY. Ms Moffet is affiliated with the Department of Pediatrics, Division of Blood and Marrow Transplant, Duke Children's Hospital, Duke University, Durham, NC. Dr Hall is affiliated with the Department of Pediatrics, Division of Critical Care, Nationwide Children's Hospital, The Ohio State University, Columbus, OH. Ms Pinos and Dr Tamburro are affiliated with the Department of Pediatrics, Division of Critical Care, Penn State Hershey Children's Hospital, Pennsylvania State University College of Medicine, Hershey, PA. Dr Cheifetz is affiliated with the Department of Pediatrics, Division of Critical Care, Duke Children's Hospital, Duke University, Durham, NC.
}

The authors have disclosed no conflicts of interest.

A version of this paper was presented at the American Thoracic Society conference, held May 19-24, 2017, in Washington, D.C.

Correspondence: Courtney M Rowan, MD, Riley Hospital for Children, 705 Riley Hospital Dr., Phase 2, 4B, Indianapolis, IN 46202. E-mail: coujohns@iu.edu.

DOI: $10.4187 /$ respcare. 05765 
The study was performed at the following institutions: Riley Hospital for Children at Indiana University School of Medicine; Joseph M Sanzari Children's Hospital at Hackensack University Medical Center; Medical College of Wisconsin, Children's Hospital of Wisconsin; Children's Hospital of Philadelphia University of Pennsylvania Perelman School of Medicine; University of Minnesota, Masonic Children's Hospital; Weil Cornell Medical College, New York Presbyterian Hospital; Dana-Farber Cancer Institute; Children's Hospital of Los Angeles; University of Washington and Seattle Children's Hospital; Duke Children's Hospital; Nationwide Children's Hospital; and Penn State Children's Hospital.

A total of 222 patients were included in the original database, of which 85 subjects received HFOV at some point during their course of mechanical ventilation. These patients served as the subjects for the description of HFOV utilization in this population as well as for the comparison of survivors to nonsurvivors. We collected the following data points: demographics, transplant variables, length of pediatric ICU stay, duration of mechanical ventilation, duration of HFOV, use of vasoactive agents during the course of mechanical ventilation, use of renal replacement therapy during the course of mechanical ventilation, use of inhaled nitric oxide, respiratory infections, and survival. Respiratory parameters, settings, and arterial blood gas data were collected every $6 \mathrm{~h}$ for the day before, the day of, and day after transition to HFOV. Oxygenation index (OI) was calculated as $\left(\mathrm{F}_{\mathrm{IO}_{2}} \times \overline{\mathrm{P}}_{\mathrm{aw}} / \mathrm{P}_{\mathrm{aO}}\right) \times 100$, where $\overline{\mathrm{P}}_{\mathrm{aw}}$ indicates mean airway pressure. Oxygen saturation index was calculated as $\left(\mathrm{F}_{\mathrm{IO}_{2}} \times \overline{\mathrm{P}}_{\mathrm{aw}} / \mathrm{P}_{\mathrm{aO}}\right) \times 100$ if the pulse oximeter saturation was $\leq 97 \% .{ }^{17}$

All but 2 of the subjects had severe pediatric ARDS as defined using the OI or oxygen saturation index criteria established by the Pediatric Acute Lung Injury and Consensus Conference (PALICC); to assess the value of timing of HFOV, subjects were categorized into 3 groups: subjects managed only with conventional mechanical ventilation, subjects placed on HFOV early in the course of mechanical ventilation, and subjects transitioned to HFOV late in the mechanical ventilation course. Early HFOV was defined a priori as being transitioned to HFOV by day 2 of mechanical ventilation, with the day of intubation being day 0 .

\section{Statistical Analysis}

Continuous variables are presented as medians with interquartile ranges (IQRs) and were compared with a Wilcoxon rank-sum test or a Kruskal-Wallis analysis. A Dunn test was run to conduct a pairwise comparison for variables that were statistically significant on a Kruskal-Wallis analysis when comparing the 3 groups of conventional mechanical ventilation, early HFOV, and late HFOV. Categorical variables are presented as frequencies or percentages and were compared with chi-square analysis or a Fisher exact test where appropriate.

\section{Results}

There were 85 pediatric hematopoietic cell transplant subjects transitioned to HFOV. Of these 85 subjects, only 20 subjects survived to pediatric ICU discharge for an overall survival rate of $23.5 \%$. At $180 \mathrm{~d}$ after pediatric ICU discharge, only 14 of the 20 subjects were still alive, rendering a 180 -d survival rate of $16.5 \%$ for the whole HFOV cohort. Demographics and those categorized by survival are displayed in Table 1. Of note, survivors were more likely to be female $(P=.047)$. Interestingly, there was a predominance of acute lymphoblastic leukemia in the group that survived compared to those who died (50\% vs $20 \%, P=.008)$. Of the 20 surviving subjects, 10 had acute lymphoblastic leukemia as the indication for transplant. While not reaching statistical significance, it is of note that none of the subjects with hemophagocytic lymphohistiocytosis survived a course of HFOV. There were no differences in any of the other underlying diagnoses between survivors and nonsurvivors. When underlying diagnoses were categorized as oncologic or non-oncologic, there was also no difference between survivors and nonsurvivors $(P=.13)$.

The initial HFOV settings can be found in Table 2. The median change in $\overline{\mathrm{P}}_{\mathrm{aw}}$ between the $6 \mathrm{~h}$ prior to HFOV initiation and the implementation of HFOV was an increase of $10.5 \mathrm{~cm} \mathrm{H}_{2} \mathrm{O}$, and this was not different between survivors and nonsurvivors.

Subjects who survived were transitioned to HFOV at a lower OI (25.6, IQR 21.1-36.8 vs 37.2, IQR 26.5-52.2, $P=.046)$. The median OI at $6 \mathrm{~h}$ and $24 \mathrm{~h}$ of HFOV for both survivors and nonsurvivors decreased. The median $\mathrm{OI}$ at $48 \mathrm{~h}$ for the survivors was lower than that for nonsurvivors $(P=.02)$. Additionally, the median OI for nonsurvivors was almost the same at $24 \mathrm{~h}, 48 \mathrm{~h}$, and at discontinuation of HFOV (Table 3 ).

Survivors were transitioned to HFOV earlier in the course of mechanical ventilation. Their median day of transition from conventional mechanical ventilation to HFOV was $0 \mathrm{~d}$ (IQR $0-1.5$ ) versus $2 \mathrm{~d}$ (IQR $0-9)$ for nonsurvivors, $P=.002$. Table 4 illustrates common critical care interventions by survival status. Seventeen of the 20 survivors were transitioned by day 2 of invasive mechanical ventilation. Those transitioned to HFOV early had a higher survival than those transitioned late $(32.7 \%[n=17]$ vs $9.1 \%[n=3], P=.02)$. No subjects who were transitioned to HFOV after 1 week of conventional mechanical ventilation survived. 
Table 1. Demographics Assess by Survival Status to Pediatric ICU Discharge

\begin{tabular}{|c|c|c|c|c|}
\hline Variable & All HFOV $(N=85)$ & Survivors $(n=20)$ & Nonsurvivors $(n=65)$ & $P$ \\
\hline Female subjects & $43(50.6 \%)$ & $14(70.0 \%)$ & $29(44.6 \%)$ & .047 \\
\hline Age at pediatric ICU admit, y & $6.8(1.6-14.8)$ & $8.5(1.5-14.8)$ & $6.5(1.7-14.8)$ & .69 \\
\hline \multicolumn{5}{|l|}{ Race } \\
\hline Caucasian & $51(60.0 \%)$ & $12(60.0 \%)$ & $39(60.0 \%)$ & \multirow{5}{*}{$>.99$} \\
\hline African American & $8(9.4 \%)$ & $2(10.0 \%)$ & $6(9.2 \%)$ & \\
\hline Asian & $5(5.9 \%)$ & $1(5.0 \%)$ & $4(6.2 \%)$ & \\
\hline Other & $18(21.2 \%)$ & $4(20.0 \%)$ & $14(21.5 \%)$ & \\
\hline Unknown & $3(3.5 \%)$ & $1(5.0 \%)$ & $2(3.1 \%)$ & \\
\hline First transplant & $75(88.2 \%)$ & $18(90.0 \%)$ & $57(87.7 \%)$ & $>.99$ \\
\hline \multicolumn{5}{|l|}{ Type of transplant } \\
\hline Bone marrow & $34(40.0 \%)$ & $8(40.0 \%)$ & $26(40.0 \%)$ & \multirow[t]{3}{*}{.23} \\
\hline Cord blood & $43(50.6 \%)$ & $12(60.0 \%)$ & $31(47.7 \%)$ & \\
\hline Peripheral blood & $8(9.4 \%)$ & & $8(12.3 \%)$ & \\
\hline Related donor & $16(18.8 \%)$ & $4(20.0 \%)$ & $12(18.5 \%)$ & $>.99$ \\
\hline Underlying oncology diagnosis & $47(55.3 \%)$ & $14(70.0 \%)$ & $33(50.8 \%)$ & .13 \\
\hline \multicolumn{5}{|l|}{ Reason for transplant } \\
\hline Acute lymphoblastic leukemia & $23(27.1 \%)$ & $10(50.0 \%)$ & $13(20.0 \%)$ & .008 \\
\hline Acute myeloid leukemia & $21(24.7 \%)$ & $4(20.0 \%)$ & $17(26.2 \%)$ & .77 \\
\hline Immunodeficiency & $8(9.4 \%)$ & $3(15.0 \%)$ & $5(7.7 \%)$ & .38 \\
\hline Hemophagocytic lymphohistiocytosis & $8(9.4 \%)$ & $0(0 \%)$ & $8(12.3 \%)$ & .19 \\
\hline Bone marrow failure & $8(9.4 \%)$ & $1(5.0 \%)$ & $7(10.8 \%)$ & .67 \\
\hline Metabolic syndrome & $10(11.8 \%)$ & $2(10.0 \%)$ & $8(12.3)$ & $>.99$ \\
\hline Hemoglobinopathies & $2(2.4 \%)$ & $0(0 \%)$ & $2(3.1 \%)$ & $>.99$ \\
\hline Lymphomas & $1(1.2 \%)$ & $0(0 \%)$ & $1(1.5 \%)$ & $>.99$ \\
\hline Myelodysplastic & $1(1.2 \%)$ & $0(0 \%)$ & $1(1.5 \%)$ & $>.99$ \\
\hline Myeloproliferative & $1(1.2 \%)$ & $0(0 \%)$ & $1(1.5 \%)$ & $>.99$ \\
\hline Other & $2(2.4 \%)$ & $0(0 \%)$ & $2(3.1 \%)$ & $>.99$ \\
\hline Positive respiratory culture & $39(45.9 \%)$ & $7(35.0)$ & $32(49.2 \%)$ & .26 \\
\hline Duration of conventional mechanical ventilation prior to HFOV, $\mathrm{d}$ & $1.0(0.0-5.0)$ & $0.0(0.0-1.5)$ & $2.0(0.0-9.0)$ & .002 \\
\hline Duration of HFOV, $d$ & $5.0(2.0-9.0)$ & $5.0(2.0-8.0)$ & $4.0(1.0-11.0)$ & .93 \\
\hline Inhaled nitric oxide & $35(41.2 \%)$ & $3(15.0 \%)$ & $32(49.2 \%)$ & .007 \\
\hline NIV prior to invasive mechanical ventilation & $46(54.1 \%)$ & $10(50.0 \%)$ & $36(55.4 \%)$ & .67 \\
\hline Renal replacement therapy & $33(38.8 \%)$ & $7(35.0 \%)$ & $26(40.0 \%)$ & 69 \\
\hline Vasopressors/inotropes & $70(82.4 \%)$ & $16(80.0 \%)$ & $54(83.1 \%)$ & .75 \\
\hline
\end{tabular}

Table 2. Starting Settings on HFOV Compared by Survival Status

\begin{tabular}{lccr}
\hline \multicolumn{1}{c}{ HFOV Setting } & All & Survivors & Nonsurvivors \\
\hline Mean airway pressure, $\mathrm{cm} \mathrm{H}_{2} \mathrm{O}$ & $32(28-36)$ & $32(25-35)$ & $32(28-36)$ \\
Hertz & $6(5-8)$ & $6(5-9)$ & $6(5-8)$ \\
Amplitude, $\mathrm{cm} \mathrm{H}_{2} \mathrm{O}$ & $65(52-74)$ & $58(45-70)$ & $65(52-74)$
\end{tabular}

Data are presented as medians with interquartile ranges. Survivors were compared to nonsurvivors using a Wilcoxon rank-sum test. $\mathrm{HFOV}=$ high-frequency oscillatory ventilation

There was no difference between survivors and nonsurvivors in the need for vasoactive agents or renal replacement therapy. Nonsurvivors were more likely to have been placed on inhaled nitric oxide $(P=.007)$ (Table 4$)$. The institutional effect for this population was also examined, and no institutional effect on mortality was found $(P=.41)$. In addition, no statistical difference in the application of early or late HFOV by the institution was seen $(P=.06)$. 
hFOV Use in Pediatric Hematopoietic Cell Transplant Recipients

Table 3. Oxygenation Index and Oxygen Saturation Index Over Time Assessed by Pediatric ICU Survival Status

\begin{tabular}{|c|c|c|c|c|c|c|}
\hline Time on HFOV & $6 \mathrm{~h}$ Prior & Start & $6 \mathrm{~h}$ & $24 \mathrm{~h}$ & $48 \mathrm{~h}$ & Stop \\
\hline \multicolumn{7}{|l|}{ Oxygenation Index } \\
\hline Survivors & $26.5(6.4-46.6)$ & $25.6(21.1-36.8)$ & $23.3(17.8-32.5)$ & $18.7(10.7-24.2)$ & $10.7(7.9-20.1)$ & $6.1(4.0-9.5)$ \\
\hline Nonsurvivors & $25.6(14.0-32.9)$ & $37.2(26.5-52.2)$ & $32.9(19.7-48.3)$ & $21.5(15.6-31.5)$ & $21.5(13.9-28.0)$ & $20.9(10.5-48.0)$ \\
\hline$P$ & .97 & .046 & .07 & .29 & .02 & $<.001$ \\
\hline \multicolumn{7}{|c|}{ Oxygen Saturation Index } \\
\hline Survivors & $17.1(17.0-22.5)$ & $28.3(23.2-31.5)$ & $18.2(14.1-27.8)$ & $14.4(12.0-20.3)$ & $10.5(9.4-14.8)$ & $5.8(4.7-9.2)$ \\
\hline Nonsurvivors & $19.9(11.2-26.8)$ & $32.5(27.5-38.7)$ & $25.7(21.1-34.3)$ & $19.3(15.6-28.1)$ & $16.0(12.3-21.8)$ & $17.9(8.6-38.9)$ \\
\hline$P$ & .545 & .050 & .07 & .12 & .03 & $<.001$ \\
\hline
\end{tabular}

Data are presented as medians (interquartile range). Start values were obtained at the time point closest to initiating high-frequency oscillatory ventilation (HFOV).

Table 4. Comparison of Common Critical Care Interventions and Duration of Ventilation by Survivor Status

\begin{tabular}{|c|c|c|c|c|}
\hline Interventions and Duration & Entire Cohort & Survivors & Nonsurvivors & $P$ \\
\hline Use of inhaled nitric oxide & $35(41.2 \%)$ & $3(15.0 \%)$ & $32(49.2 \%)$ & .007 \\
\hline Identified respiratory pathogen & $39(45.9 \%)$ & $7(35.0 \%)$ & $32(49.2 \%)$ & .26 \\
\hline Renal replacement therapy & $33(38.8 \%)$ & $7(35.0 \%)$ & $23(40.0 \%)$ & .69 \\
\hline Vasoactive agents & $70(82.4 \%)$ & $16(80.0 \%)$ & $54(83.1 \%)$ & .75 \\
\hline Duration of invasive mechanical ventilation, $\mathrm{d}$ & $16.0(8.0-26.0)$ & $14.0(9.0-24.0)$ & $17.0(7.0-26.0)$ & .87 \\
\hline Duration of HFOV, $\mathrm{d}$ & $5.0(2.0-9.0)$ & $5.0(2.0-8.0)$ & $4.0(1.0-11.0)$ & .93 \\
\hline Duration of invasive mechanical ventilation prior to $\mathrm{HFOV}, \mathrm{d}$ & $1.0(0-5.0)$ & $0.0(0-1.5)$ & $2.0(0-9.0)$ & .002 \\
\hline
\end{tabular}

Data are presented as medians (interquartile range) and were compared using Wilcoxon rank sum test, or as frequency (\%) and compared using chi-square or Fisher exact tests where appropriate. $\mathrm{HFOV}=$ high-frequency oscillatory ventilation

\section{Conventional Mechanical Ventilation Versus Early HFOV Versus Late HFOV in Subjects With Severe Pediatric ARDS}

Of the 129 subjects included in this comparative analysis, 50 were in the early HFOV group, 33 were in the late HFOV group, and 46 were in the conventional mechanical ventilation group. The conventional mechanical ventilation group represents the cohort that had severe pediatric ARDS according to the PALICC definition and did not transition to HFOV. Two subjects were excluded from the early HFOV group because they had only moderate pediatric ARDS at time of conversion to HFOV. Both of these subjects survived. There was a difference in age among these groups $(P=.006)$. On pairwise testing, those ventilated with only conventional mechanical ventilation were older than those in the late HFOV group $(P=.003)$, but there was no statistical difference with early HFOV. There was no difference in gender, oncology diagnosis, source of hematopoietic cell transplant, or related donor status between the 3 groups (Table 5).

There was a trend toward a lower survival rate in the late HFOV group $(P=.08)$, with the early HFOV group having the highest rate of survival at $30.0 \%$ (Table 5). The duration of mechanical ventilation was different between groups $(P=.03)$, but on pairwise testing there was no difference in the total duration of mechanical ventilation between the conventional mechanical ventilation and early HFOV groups. Those ventilated with late HFOV had a longer duration of mechanical ventilation compared to the early HFOV group $(P=.039)$. Ventilator-free days at $28 \mathrm{~d}$ was examined. The distribution of ventilator-free days was statistically different; however, the median number of ventilator-free days for all groups was 0 (Table 5). Interestingly, in the late HFOV group, every subject had 0 ventilator-free days. In the conventional mechanical ventilation group, $83 \%$ of subjects $(n=39)$ had 0 ventilator-free days, and in the early HFOV group, $72 \%$ of subjects $(n=36)$ had 0 ventilator-free days. On pairwise analysis, ventilator-free days for the conventional mechanical ventilation was not statistically different from ventilator-free days for the early HFOV group, but ventilator-free days for the early HFOV group was different from that of the late HFOV group $(P=.002)$. The use of noninvasive ventilation prior to intubation was similar $(P=.51)$. Vasoactive medication use was common in all groups and was not statistically different $(P=.15)$. The use of renal replacement therapy was also not different among groups $(P=.37)$. 
hFov Use in Pediatric Hematopoietic Cell Transplant Recipients

Table 5. Comparison of Demographic and Critical Care Variables Stratified by Mechanical Ventilation Practice

\begin{tabular}{|c|c|c|c|c|}
\hline Variable & Conventional Mechanical Ventilation $(n=46)$ & Early HFOV $(n=50)^{*}$ & Late $\operatorname{HFOV}(n=33)$ & $P$ \\
\hline Age, y & $12.3(5.2-16.9)$ & $9.8(2.6-15.3)$ & $3.2(0.9-10.5)$ & .006 \\
\hline Female subjects & $22(47.8 \%)$ & $22(44.0 \%)$ & $19(57.6 \%)$ & .47 \\
\hline Oncology Diagnosis & $23(50.0 \%)$ & $30(60.0 \%)$ & $15(45.5 \%)$ & .39 \\
\hline \multicolumn{5}{|c|}{ Hematopoietic cell transplant source } \\
\hline Bone Marrow & $23(50.0 \%)$ & $15(30.0 \%)$ & $18(54.5 \%)$ & .07 \\
\hline Cord Blood & $16(34.8 \%)$ & $28(56.0 \%)$ & $14(42.4 \%)$ & \\
\hline Peripheral Blood & $7(15.2 \%)$ & $7(14.0 \%)$ & $1(3.0 \%)$ & \\
\hline Related Donor & $6(13.0 \%)$ & $8(16.0 \%)$ & $8(24.2 \%)$ & .41 \\
\hline NIV prior to intubation & $26(56.5 \%)$ & $28(56.0 \%)$ & $17(52.5 \%)$ & .89 \\
\hline Vasoactive agents & $43(93.5 \%)$ & $42(84.0 \%)$ & $26(78.8 \%)$ & .15 \\
\hline Renal replacement therapy & $20(44.4 \%) \dagger$ & $22(44.0 \%)$ & $10(30.3 \%)$ & .37 \\
\hline Length of pediatric ICU stay, $d$ & $20.0(9.0-41.0)$ & $18.0(10.0-30.0)$ & $20.0(14.0-43.0)$ & .19 \\
\hline Mechanical ventilation, $\mathrm{d}$ & $11.5(3.0-27.0)$ & $11.5(5.0-19.0)$ & $18.0(13.0-30.0)$ & .030 \\
\hline Ventilator-free days at $28 \mathrm{~d}$ & $0(0-0)$ & $0(0-11)$ & $0(0-0)$ & .004 \\
\hline Survival & $11(23.9 \%)$ & $15(30.0 \%)$ & $3(9.1 \%)$ & .08 \\
\hline
\end{tabular}

Data are presented as medians (interquartile range) and were compared using Kruskal-Wallis test, or as frequency (\%) and compared using an extended Fisher exact test.

* 2 subjects were excluded from the early HFOV group because they were started on HFOV when they had moderate pediatric ARDS.

$\dagger 1$ subject was missing data regarding renal replacement therapy from this group.

HFOV = high-frequency oscillatory ventilation

NIV = noninvasive ventilation

\section{Discussion}

Our study has 3 significant findings. The first is that subjects who were transitioned to HFOV earlier in the course of invasive mechanical ventilation had improved survival when compared to subjects transitioned to HFOV late in their course of mechanical ventilation. Second, those who survived continued to have improvement in their oxygenation; those who died had a plateau in the improvement of their OI at $48 \mathrm{~h}$. The last finding in this cohort is that the outcomes were not statistically different when comparing subjects with severe pediatric ARDS who were managed with conventional mechanical ventilation alone to those who were transitioned early to HFOV.

HFOV has been a longstanding tool in the treatment of pediatric ARDS. After HFOV demonstrated a decrease in the risk of chronic lung disease in premature babies, HFOV gained interest for use in pediatric ARDS. ${ }^{18}$ Arnold et al ${ }^{11}$ found promising results with the application of HFOV in ARDS, illustrating improved oxygenation and decreased need for supplemental $\mathrm{O}_{2}$ at $30 \mathrm{~d}$. However, there was no difference in the duration of mechanical ventilation or survival. Multiple studies have shown that HFOV can improve oxygenation. ${ }^{12-14,19-21}$ Despite this improvement in oxygenation, studies have not confirmed a mortality difference. Like our study, however, Arnold et al ${ }^{19}$ found in a heterogeneous population that an improvement in OI discriminated between survivors and nonsurvivors, and Yehya et $\mathrm{al}^{22}$ found the same in immunocompromised subjects.
When comparing subjects on HFOV, most had an improvement in oxygenation, but those who survived had a more dramatic and sustained OI improvement. In this highacuity cohort, continued oxygenation improvement was associated with survival. It is likely that the continued improvement in oxygenation represents recoverable lung injury, whereas subjects who experienced a plateau in their OI improvement may have had unrecoverable lung damage. While the nonsurvivors did have a lower OI at $48 \mathrm{~h}$ and at the conclusion of HFOV, it was not a clinically notable improvement. The median OI at both points remained consistent with oxygenation criteria for severe pediatric ARDS. A greater use of inhaled nitric oxide was seen in the nonsurvivor population. This likely reflects the severity of lung disease in nonsurvivors. Potentially this rescue intervention was applied more often in this group due to the lack of sustained improvement in oxygenation.

With this demonstration of improvement in oxygenation, the critical care community has sought to find the best way to apply this modality. The improvement in oxygenation is encouraging, but the lack of clinically relevant positive changes in outcomes continues to be a source of frustration. In this cohort, early application of HFOV (ie, within the first $2 \mathrm{~d}$ of invasive mechanical ventilation) was associated with improved survival compared to late application of HFOV. This is in line with suggestions from previously published literature. ${ }^{12,13}$ Perhaps this early approach with HFOV allows for earlier, more aggressive lung recruitment. However, this directly contradicts more recent literature that questions the current approach to HFOV, sug- 
gesting that it is associated with worse mortality and longer duration of mechanical ventilation in the general pediatric population. ${ }^{15,16}$ In the study by Bateman et al, ${ }^{15}$ ventilatorfree days were lower in the early HFOV cohort as compared to those who were managed with only conventional mechanical ventilation or with late HFOV. This study's cohort is unique from the general pediatric population in that they were at higher risk for a variety of lung diseases, including severe infections, diffuse alveolar hemorrhage, idiopathic pulmonary syndrome, lung graft-versus-host disease, and bronchiolitis obliterans. ${ }^{6,8,23}$ The recoverability of each of these diseases is variable. Additionally, these patients have generally been exposed to previous lungtoxic drugs and infections, which placed them at risk to be admitted to the pediatric ICU with existing lung disease. Therefore, the findings from studies of the general pediatric population may not be applicable to our unique and highly vulnerable patient population.

To begin to understand the effectiveness of HFOV compared to conventional mechanical ventilation, we isolated subjects with severe pediatric ARDS, as defined by PALICC guidelines, treated with conventional mechanical ventilation alone and compared them to the early and late HFOV groups. In this analysis, we found data that contradict previously published data by Bateman et al. ${ }^{15}$ In this secondary analysis of the RESTORE database, they found that those treated with early HFOV had a longer duration of mechanical ventilation. In our specialized cohort, this was not the case. Those treated with early HFOV had the same duration of mechanical ventilation as those with severe pediatric ARDS treated with conventional mechanical ventilation alone. Additionally, the early HFOV group had the highest survival at $30 \%$, although this did not meet statistical significance. Isolating those treated with HFOV later in the course of mechanical ventilation, we found this group to have both a higher mortality and a longer duration of mechanical ventilation.

Our study does have limitations that are inherent to all retrospective analyses. We were limited by the availability of the data, particularly blood gas data, to calculate OI for every subject at each time point. We hoped to negate some of this limitation by collecting OI at multiple time points to obtain a more complete picture of the degree of oxygenation failure in this population. Additionally, the study is limited by a diverse approach to both transitioning and utilization of HFOV. Because this study was retrospective, subjects were transitioned to HFOV at the discretion of the clinical care team. Despite these limitations, this study is strengthened by the large cohort of subjects from multiple centers, which improves the generalizability and the frequency of ventilator and blood gas data collected throughout the study.

\section{Conclusion}

In pediatric allogeneic hematopoietic cell transplant subjects, those treated with HFOV had a lower overall pediatric ICU survival at $23.5 \%$ compared to the reported survival rates of $40-50 \%$ of those receiving all types of mechanical ventilation..$^{5,24,25}$ However, this is more likely a reflection of the severity of lung injury than of the modality itself. Furthermore, there is a suggestion that early application of HFOV may be of benefit. A prospective study is necessary to answer the questions about the timing of HFOV and the overall benefit of this modality. While it is clear that a prospective trial is warranted to make firm recommendations, our data suggest that the late use of HFOV in this population, especially after $7 \mathrm{~d}$ of conventional mechanical ventilation, should be undertaken with caution.

\section{REFERENCES}

1. Tamburro RF, Barfield RC, Shaffer ML, Rajasekaran S, Woodard P, Morrison RR, et al. Changes in outcomes (1996-2004) for pediatric oncology and hematopoietic stem cell transplant patients requiring invasive mechanical ventilation. Pediatr Crit Care Med 2008;9(3): 270-277.

2. van Gestel JP, Bierings MB, Dauger S, Dalle JH, Pavlicek P, Sedlacek $\mathrm{P}$, et al. Outcome of invasive mechanical ventilation after pediatric allogeneic hematopoietic SCT: results from a prospective, multicenter registry. Bone Marrow Transplant 2014;49(10):12871292.

3. Wermke M, Schiemanck S, Hoffken G, Ehninger G, Bornhauser M, Illmer T. Respiratory failure in patients undergoing allogeneic hematopoietic SCT: a randomized trial on early non-invasive ventilation based on standard care hematology wards. Bone Marrow Transplant 2012;47(4):574-580.

4. Kaya Z, Weiner DJ, Yilmaz D, Rowan J, Goyal RK. Lung function, pulmonary complications, and mortality after allogeneic blood and marrow transplantation in children. Biol Blood Marrow Transplant 2009;15(7):817-826.

5. Duncan CN, Lehmann LE, Cheifetz IM, Greathouse K, Haight AE, Hall MW, et al. Clinical outcomes of children receiving intensive cardiopulmonary support during hematopoietic stem cell transplant. Pediatr Crit Care Med 2013;14(3):261-267.

6. Cerveri I, Zoia MC, Fulgoni P, Corsico A, Casali L, Tinelli C, et al. Late pulmonary sequelae after childhood bone marrow transplantation. Thorax 1999;54(2):131-135.

7. Leneveu H, Bremont F, Rubie H, Peyroulet MC, Broue A, Suc A, et al. Respiratory function in children undergoing bone marrow transplantation. Pediatr Pulmonol 1999;28(1):31-38.

8. Griese M, Rampf U, Hofmann D, Fuhrer M, Reinhardt D, BenderGotze C. Pulmonary complications after bone marrow transplantation in children: twenty-four years of experience in a single pediatric center. Pediatr Pulmonol 2000;30(5):393-401.

9. Rowan CM, Smith LS, Loomis A, McArthur J, Gertz SJ, Fitzgerald $\mathrm{JC}$, et al. Pediatric acute respiratory distress syndrome in pediatric allogeneic hematopoietic stem cell transplants: a multicenter study. Pediatr Crit Care Med 2017;18(4):304-309.

10. Rosenberg RB, Broner CW, Peters KJ, Anglin DL. High-frequency ventilation for acute pediatric respiratory failure. Chest 1993;104(4): 1216-1221. 
11. Arnold JH, Hanson JH, Toro-Figuero LO, Gutiérrez J, Berens RJ, Anglin DL. Prospective, randomized comparison of high-frequency oscillatory ventilation and conventional mechanical ventilation in pediatric respiratory failure. Crit Care Med 1994;22(10):1530-1539.

12. Brogan TV, Bratton SL, Meyer RJ, O'Rourke PP, Jardine DS. Nonpulmonary organ failure and outcome in children treated with highfrequency oscillatory ventilation. J Crit Care 2000;15(1):5-11.

13. Slee-Wijffels FY, van der Vaart KR, Twisk JW, Markhorst DG, Plötz FB. High-frequency oscillatory ventilation in children: a single-center experience of 53 cases. Crit Care 2005;9(3):R274-R279.

14. Ben Jaballah N, Khaldi A, Mnif K, Bouziri A, Belhadj S, Hamdi A, et al. High-frequency oscillatory ventilation in pediatric patients with acute respiratory failure. Pediatr Crit Care Med 2006;7(4):362-367.

15. Bateman ST, Borasino S, Asaro LA, Cheifetz IM, Diane S, Wypij D, et al. Early high-frequency oscillatory ventilation in pediatric acute respiratory failure: a propensity score analysis. Am J Respir Crit Care Med 2016;193(5):495-503.

16. Gupta P, Green JW, Tang X, Gall CM, Gossett JM, Rice TB, et al. Comparison of high-frequency oscillatory ventilation and conventional mechanical ventilation in pediatric respiratory failure. JAMA Pediatr 2014;168(3):243-249.

17. Thomas NJ, Shaffer ML, Willson DF, Shih MC, Curley MA. Defining acute lung disease in children with the oxygenation saturation index. Pediatr Crit Care Med 2010;11(1):12-17.

18. Randomized study of high-frequency oscillatory ventilation in infants with severe respiratory distress syndrome. HiFO Study Group. J Pediatr 1993;122(4):609-619.
19. Arnold JH, Anas NG, Luckett P, Cheifetz IM, Reyes G, Newth CJ, et al. High-frequency oscillatory ventilation in pediatric respiratory failure: a multicenter experience. Crit Care Med 2000;28(12):39133919.

20. Fioretto JR, Batista KA, Carpi MF, Bonatto RC, Moraes MA, Ricchetti SM, et al. High-frequency oscillatory ventilation associated with inhaled nitric oxide compared to pressure-controlled assist/control ventilation and inhaled nitric oxide in children: randomized, non-blinded, crossover study. Pediatr Pulmonol 2011;46(8):809-816.

21. Yehya N, Topjian AA, Lin R, Berg RA, Thomas NJ, Friess SH. High frequency oscillation and airway pressure release ventilation in pediatric respiratory failure. Pediatr Pulmonol 2014;49(7):707-715.

22. Yehya N, Topjian AA, Thomas NJ, Friess SH. Improved oxygenation 24 hours after transition to airway pressure release ventilation or high-frequency oscillatory ventilation accurately discriminates survival in immunocompromised pediatric patients with acute respiratory distress syndrome. Pediatr Crit Care Med 2014;15(4):e147-e156.

23. Rowan CM, Baloglu O, McArthur J. Non-infectious pulmonary complications of hematopoietic stem cell transplantation. Journal of Pediatric Critical Care 2014;3(3):133-146.

24. Rowan CM, Gertz SJ, McArthur J, Fitzgerald JC, Nitu ME, Loomis A, et al. Invasive mechanical ventilation and mortality in pediatric hematopoietic stem cell transplantation: a multicenter study. Pediatr Crit Care Med 2016;17(4):294-302.

25. Chima RS, Daniels RC, Kim MO, Li D, Wheeler DS, Davies SM, et al. Improved outcomes for stem cell transplant recipients requiring pediatric intensive care. Pediatr Crit Care Med 2012;13(6):e336-e342.

This article is approved for Continuing Respiratory Care Education credit. For information and to obtain your CRCE

(free to AARC members) visit www.rcjournal.com 